\title{
Design Strategies and Methods Research in Comprehensive Designing Experiment
}

\author{
Xinfang Wang ${ }^{1}$ \\ ${ }^{1}$ Department of Chemistry, Dezhou University, Dezhou, China \\ Correspondence: Xinfang Wang, Department of Chemistry, Dezhou University, Dezhou 253023, China. Tel: \\ 86-534-898-7866. E-mail: dzxywxf@126.com
}

Received: April 5, 2012 Accepted: May 27, 2012 Online Published: August 17, 2012

doi:10.5539/ass.v8n11p160

URL: http://dx.doi.org/10.5539/ass.v8n11p160

The research is funded by Shandong Education Science 'ten-one-five' planning projects (115GG45) and the teaching research project of Dezhou University (JYKT-A07003 and SYJS-B11009).

\begin{abstract}
The comprehensive designing experiment is very important to train the students' scientific thinking ability and improve the students' comprehensive quality in inorganic chemistry experiment. This article introduces a kind of teaching method which can cultivate students' experimental design capacity. By guiding the student to explore the design strategy and idea in comprehensive design experiment, the article focuses on the experiment "preparation of potassium nitrate by using double decomposition method" as a case.
\end{abstract}

Keywords: comprehensive designing experiment, experimental design capacity

\section{Introduction}

Chemistry is a science based on experiment. Chemical experiment is essential for the students to acquire chemical knowledge and skills, train the scientific way of thinking, cultivate scientific spirit and character, etc. Inorganic chemical experiment is the first compulsory foundation course for universities of the chemical industry, chemistry, material, textile, metallurgy and other relevant profession. It is not only important for its knowledge teaching, but also for students to learn other follow-up experiment course and theory course. In addition, it is very important for the development of chemistry and chemical engineering and other professional disciplines.

\section{Characteristics of Comprehensive Designing Experimental and the Choice of Teaching Methods}

Currently, the types of inorganic chemistry experiment include basic operation experiment, basic principle experiment, chemical element experiment and comprehensive designing experiment. The first three types of experiments which belong to traditional verification experiments focus on fostering students' capability of generous experimental skills and techniques and laying a solid foundation in their lifelong development. But comprehensive designing experiment, a more high level of experiment type, focus on training students' ability to analyze and solve problems, and paying attention to the developing requirements of students and society. It is important for the students to master a certain inorganic chemistry experiment methods, the basic operation skills and experimental operation proficiency, but it is more important to know how to design the experiments. The students can do research scientific activities only after mastering the experimental design method, so improving students' comprehensive experimental skills, cultivating the students' scientific research and innovation spirit appear especially important in comprehensive designing experimental study. Recently in the inorganic chemistry experiment teaching practice, we have been doing research on the experimental teaching method and mode. The teaching experience preliminary summarized by us is the teachers must guide the student to study the experimental design strategy and idea and the experimental design concept. Only by this we can stimulate students' interest in learning experiments, cultivate students' thinking ability and improve students' science experiment ability. That is, it is a research-based experimental teaching. The research-based experimental teaching is a teaching mode that teachers lead students to study the experimental design strategies and methods. This teaching pattern mainly emphasizes the "guiding function" of the teachers and the "active learning position" of the students, by exploring experimental design issues as the teaching contents. In this context, we 
will introduce the application of this teaching method by taking the experiment "preparation potassium nitrate" as an example.

\section{Design Strategies and Methods of the Experiment "Preparation Potassium Nitrate"}

\subsection{Designing the Exploratory Questions Elaborately and Developing the Teacher's "Guiding" Role}

This teaching model puts forward higher requirements for the teachers. Teachers must be in-depth preparation, fully tap the experiment content, refine the experimental design ideas, and study the experimental content with research-based teaching methods. The main intention is not to solve some specific issues (such as the experimental amount of drugs, steps, note, etc) in the traditional classes, but to provide a thinking and research platform for students. This mode implies that the teachers will need to guide students thinking as often as possible so that they can do several exploratory research and some idea generation exercises in class. The students can find the design of this experimental is so clever after thinking and calculation. By this students can deep sense chemical experimental design strategies and methods so that the teacher can achieve good teaching results.

In this experiment we design five exploratory questions as follows.

Question 1: The reactants used in the experiment include $22 \mathrm{~g} \mathrm{NaNO}, 15 \mathrm{~g} \mathrm{KCl}$ and $35 \mathrm{ml}$ distilled water. How to confirm the best consumption of water?

Question 2: Why the reactants $\mathrm{NaNO}_{3}$ and $\mathrm{H}_{2} \mathrm{O}$ are excess in the experiment?

Question 3: Why we don't stop heating until the original solution volume remains two-thirds? Theoretically, how much $\mathrm{KNO}_{3}$ should be gotten finally?

Question 4: what product could be harvested after the cooling of the filtrate?

Question 5: How much the product purity can achieve theoretically after recrystallization process?

\subsection{Inquiring the Answer of Exploratory Questions and Developing the Students' "Active Learning”}

The reagents used in the experiment are a mixture of $\mathrm{NaNO}_{3}$ and $\mathrm{KCl}$. The experimental phenomena is that colorless crystals are crystallized from the colorless solution. Many students doubt if the crystal is $\mathrm{KNO}_{3}$ because the experimental phenomena lacks of convincing. We lead the students to think and calculate the above exploratory questions for developing the students' "active learning". After calculation, the students really understand the expected results of the experiment and experienced the thinking process of the experiment. This kind of teaching method can stimulate students' positive thinking and understand the experiment in a deeper level rather than remain on the surface of the contents in the experiments. The research results in the experiment "preparation of potassium nitrate experiment" are as follows.

Answer 1: The quantities of reactants are based on the chemical reaction equation. The result of calculation is that $0.26 \mathrm{~mol}(22 \mathrm{~g}) \mathrm{NaNO}_{3}$ and $0.2 \mathrm{~mol}(15 \mathrm{~g}$ ) of $\mathrm{KCl}$ mol reaction, theoretically generate $11.8 \mathrm{~g} \mathrm{NaCl}$ and 20.2 $\mathrm{g} \mathrm{KNO}_{3}$. If the temperature of the water is $100{ }^{\circ} \mathrm{C}$, to dissolve the products needed the minimum amount of water is 29.6g. So in this experiment, the dosage of the $\mathrm{H}_{2} \mathrm{O}$ is slightly larger than the theoretical values.

Answer 2: Since this reaction is a reversible reaction, if the reactants $\mathrm{NaNO}_{3}$ and water are all excessive, it can promote the reaction to the right direction. To make the product $\mathrm{KNO}_{3}$ dissolves in $\mathrm{H}_{2} \mathrm{O}$, the consumption of water needs a little excessive.

Answer 3: When the evaporation is reach to two-thirds of the original volume, the calculation result is the crystal in the beaker is $\mathrm{NaCl}(9.2 \mathrm{~g})$, and there are all of the $\mathrm{KNO}_{3}$ product $(20.2 \mathrm{~g})$ and a small amount of $\mathrm{NaCl}$ product $(2.6 \mathrm{~g})$ in the filtrate.

Answer 4: When the filtrate was cooled to room temperature $\left(10{ }^{\circ} \mathrm{C}\right), \mathrm{KNO}_{3}$ is precipitated because of the sharp decline of the solubility ( $15.4 \mathrm{~g}$ ), in addition to a small amount of $\mathrm{NaCl}$ impurities ( $1 \mathrm{~g}$ ). After filtration, it contains a small amount of $\mathrm{KNO}_{3}$ crystals. The experimental result is the most of $\mathrm{KNO}_{3}$ is crystallized and most of $\mathrm{NaCl}$ is dissolved in the filtrate.

Answer 5: The calculation result is that $\mathrm{KNO}_{3}$ will be yields $13.5 \mathrm{~g}$ theoretically and the theoretical its purity is up to $100 \%$ after recrystallization process. But at the same time students also noted that in the recrystallization process, it lost part of $\mathrm{KNO}_{3}$. The purity of $\mathrm{KNO}_{3}$ increases, but the production rate drops. It was just like you can not get the fish and bear's paw at the same time. How to choose depends on the actual requirements. The students already know if the purity in the first synthesis procedure is not come up to the requirements, crystals can be dissolved in a small amount of solvent, then evaporated ( or cooled ) the solution, crystallized and separated. This operation is called recrystallization, which is mainly used for the improvement of product purity. Most of students only know that is a kind of way to improve the purity, but they have no idea about how this 
technology improves the purity. After quantitative calculation, they have a deeper understanding of the operation of the recrystallization theoretically.

Such teaching model in practice shows that the classroom atmosphere was active, every student's study enthusiasm was high, and the wonderful design of experiments arouses the students' desire to study experimental design. In the teaching process of this experiment, using the inquiry teaching method, we stimulated the students' curiosity, developed students' awareness of experimental design and experimental design capacity.

\subsection{Guiding the Student to Induce the Exploratory Result and Getting the Design Strategiesand Idea of the} Experiment

In the process of teaching, we mobilized the students' positive thinking and got the experimental design conclusions under the teachers' guiding. And it is not only enable students to fully grasp the purpose of this experiment, experimental content, experimental steps, and also have a full understanding and grasping of the design idea and strategy of the experimental designers. At this moment we guide the student to sum-up, raise the students' scientific thinking to the scientific concept. So in the student mind, the experimental design strategies and methods have been obvious: The experiment of potassium nitrate is prepared with potassium chloride and sodium nitrate as raw materials via double decomposition method, the reaction design basis is as follows: $\mathrm{NaNO}_{3}+\mathrm{KCl}===\mathrm{NaCl}+\mathrm{KNO}_{3}$, this reaction is reversible, so it can change the reaction direction to the right. The solubility of salt in different temperature is very significant, the solubility of sodium chloride varies insignificant with temperature but the solubility of potassium nitrate is increased rapidly with the increase of temperature. So the sodium chloride crystals are precipitated firstly from water when a certain amount solution of sodium nitrate and potassium chloride being heated a certain temperature, but potassium nitrate isn't precipitated for it's solubility in water increases with temperature. Sodium chloride can be removed after vacuum filtration when filtrate is hot, then cool this filtration to room temperature, potassium nitrate will be precipitated because of the sharp decline of the solubility. After filtration, potassium nitrate crystals that contain a small amount of sodium chloride and other impurities can be gotten. Pure potassium nitrate can be obtained after recrystallization process.

\section{Conclusions}

The experiment "preparation of potassium nitrate by using double decomposition method" is a comprehensive designing experiment in inorganic chemistry experiment. This experiment involves the knowledge of the course and a number of basic operations. In the traditional teaching way the teachers will first explain the experimental content in details, and the students will be consciously and strictly follow experimental procedures of the teaching materials. For a long time, we have been focusing on how to do the experiment. The ultimate goal is to guide students to finish a standard experiment, and then conclude the ideal experimental results. This teaching mode emphasizes on the training the experimental operation and the experimental skills, which is lack of the training students' ability to obtain knowledge, independent thinking ability, innovation ability and the corresponding professional aspects in it and limit the development of students. Now we should pay more attention to another problem: why we do this experiment in this way? That is the designing strategy and idea of the experiment itself. Because the experiment is not only the object to be learnt and mastered, but also should be a studying object to the students.

The design strategies and methods research in comprehensive designing experiment show that this teaching mode can urge the teachers seriously to study teaching materials, mine teaching contents, design the experimental teaching contents into a series of exploratory problems, create a platform for student to learn the knowledge of experimental design and solve the problems. This teaching mode stimulated the students to think and summarize the experimental design concept and idea, to reach the purpose of improving the quality of experiment teaching and cultivating students' innovative experiment ability.

\section{References}

Beijing Normal University. (2001). Inorganic chemistry experiment. Beijing: Higher Education Press.

Qin, Y. (2005). Chemistry experiment and thinking training. Guangxi education, 9, 40-41.

Wu, C., Liu, L., Ceng, X., \& Wan, Q. (2009). Novel thinking of innovation ability cultivation in chemical expermiental teaching. Laboratory Research and Exploration, 28(7), 5-6.

Xue, X. (2001). The View and suggestion about purifying potassium nitrate by crystallization process. Experiment Teaching and Apparatus, 3, 30.

Zh, C. (2001). Teaching theory in chemistry experiment. Beijing: Higher Education Press.

Zhang, L., Hua, R., \& Zhang, F. (2008). Inorganic and analytical chemistry experiment teaching and students' scientific research ability cultivation. University Laboratory Work Research, 97(3), 23-25.

Zhao, X. (2006). The characteristics of the undergraduate researchful study. Modern University Education, 5 , 105-107. 